University of Nebraska - Lincoln

DigitalCommons@University of Nebraska - Lincoln

Faculty Publications, Department of Psychology

Psychology, Department of

January 2008

\title{
Intravenous nicotine conditions a place preference in rats using an unbiased design
}

Jamie L. Wilkinson

University of Nebraska-Lincoln

Rick A. Bevins

University of Nebraska-Lincoln, rbevins1@unl.edu

Follow this and additional works at: https://digitalcommons.unl.edu/psychfacpub

Part of the Psychiatry and Psychology Commons

Wilkinson, Jamie L. and Bevins, Rick A., "Intravenous nicotine conditions a place preference in rats using an unbiased design" (2008). Faculty Publications, Department of Psychology. 265.

https://digitalcommons.unl.edu/psychfacpub/265

This Article is brought to you for free and open access by the Psychology, Department of at DigitalCommons@University of Nebraska - Lincoln. It has been accepted for inclusion in Faculty Publications, Department of Psychology by an authorized administrator of DigitalCommons@University of Nebraska - Lincoln. 
Published in Pharmacology Biochemistry and Behavior 88:3 (January 2008), pp. 256-264; doi:10.1016/j.pbb.2007.08.009

Copyright (C) 2007 Elsevier Inc. Used by permission. http://www.sciencedirect.com/science/journal/00913057

Submitted August 7, 2007; revised August 22, 2007; accepted August 24, 2007; published online September 1, 2007.

\title{
Intravenous nicotine conditions a place preference in rats using an unbiased design
}

\author{
Jamie L. Wilkinson and Rick A. Bevins* \\ Department of Psychology, University of Nebraska-Lincoln \\ * Corresponding author: 238 Burnett Hall, University of Nebraska-Lincoln, \\ Lincoln, NE 68588-0308; email rbevins1@unl.edu
}

\begin{abstract}
The rewarding effects of nicotine contribute to the chronic use of tobacco products. The place conditioning task, a widely used pre-clinical model to study drug reward, has lead to mixed results in rats when nicotine was administered subcutaneously or intraperitoneally; intravenously administered nicotine has not been examined. Further, much of the research demonstrating a nicotine-conditioned place preference in rats has used a biased design making these results susceptible to nonreward interpretations. The present study assessed whether intravenous (IV) nicotine would condition a place preference in an unbiased design and evaluated important behavioral parameters: nicotine dose, number of conditioning trials, and infusion-to-placement interval. In adult male Sprague Dawley rats, IV nicotine $(0.03 \mathrm{mg} / \mathrm{kg})$ conditioned a place preference after 8 conditioning trials. This conditioned preference was observed whether nicotine was infused 10 min before or immediately after placement in the paired environment for $10 \mathrm{~min}$; infusing nicotine immediately after removal from the paired environment did not condition a preference after 4 or 8 conditioning trials. Four conditioning trials were not sufficient to condition a preference regardless of the temporal relation between the paired environment and $0.03 \mathrm{mg} / \mathrm{kg}$ nicotine. A $0.01 \mathrm{mg} / \mathrm{kg}$ dose of nicotine did not condition a place preference after 4 or 8 trials when infused immediately upon placement in the paired environment. Intravenous nicotine $(0.03 \mathrm{mg} / \mathrm{kg})$ has rewarding effects in an unbiased design suggesting that the place conditioning protocol used in the present study might be an especially useful model for studying the processes underlying the conditioned rewarding effects of nicotine.
\end{abstract}

Keywords: Conditioned place preference, Nicotinic acetylcholine receptors, Pavlovian conditioning, Reward, Smoking,

\section{Introduction}

Smoking has consistently been reported as the number one preventable cause of premature death in the United States ([McGinnis and Foege, 1993] and [Mokdad et al., 2004]). Approximately 440,000 people die each year due to smoking-related diseases (CDC, 2005), and more than $\$ 75$ billion in annual medical costs are directly attributed to smoking. In spite of these facts, in the U.S., $21 \%$ of adults are considered current smokers (CDC, 2005). Most smokers (ca. 70\%) express a desire to quit (CDC, 2005) and approximately $40 \%$ report attempting to quit at least once in the past 12 months (CDC, 2005). Unfortunately, of those individuals that manage to quit, most relapse within the first few months of abstinence (NIDA, 2006). Although the processes responsible for tobacco use and nicotine dependence are complex, there is general consensus that the rewarding effects of nicotine are likely involved (see [Stolerman, 1991] and [Stolerman and Jarvis, 1995]). As such, a better understanding of the factors mediating the chronic use of tobacco products will require a better understanding of the behavioral and neurobiological processes of nicotine reward.

Place conditioning is a widely used pre-clinical model to study the rewarding properties of drugs in rats and mice [for reviews see Bevins and Bardo (2000) and Tzschentke (1998)]. In a typical place conditioning experiment, one distinct context (environment) is paired with the drug of interest; the subject also receives equal exposure to a second distinct context in the absence of drug. Following this conditioning phase is a choice test in which the animal receives free access to both sets of contextual cues - usually in a drug-free state. The drug is consid- 
ered rewarding if it produces an increase in the time spent in the environment paired with the drug compared to a control value [see Bevins and Cunningham (2006) for a more detailed discussion of methodological and measurement issues]. This increase in time in the drug-paired compartment is often referred to as a "conditioned place preference" and is thought to reflect a Pavlovian conditioned association between contextual stimuli and the rewarding effects of the drug (cf. [Bardo and Bevins, 2000], [Carr et al., 1989] and [Panksepp et al., 2004]).

Most drugs of abuse, such as amphetamine ([Erb and Parker, 1994] and [Lett, 1989]), cocaine ([Bevins and Bardo, 2000], [Bevins, 2005], [Nomikos and Spyraki, 1988] and [O'Dell et al., 1996]), ethanol (Cunningham et al., 1997), methamphetamine ([Cunningham and Noble, 1992] and [Gehrke et al., 2003]), and morphine ([Lett, 1989] and [Randall et al., 1998]), readily condition a place preference in rodents. Surprisingly, however, the results are less consistent with nicotine. Although the literature is mixed for rats and mice, the present research used rats and thus we will focus our discussion to the published research with rats [see Grabus et al. (2006) and Risinger and Oakes (1995) for research with mice]. Using rats some investigators have found that nicotine will condition an increase in time spent in the paired environment ([Ashby et al., 2002], [Calcagnetti and Schechter, 1994], [Dewey et al., 1999], [Forget et al., 2005], [Forget et al., 2006], [Fudala et al., 1985], [Fudala and Iwamoto, 1986], [Horan et al., 1997], [Horan et al., 2001], [Shoaib et al., 1994] and [Shram et al., 2006]). In contrast, other researchers have reported either avoidance (i.e., an aversion) of the nicotine-paired environment ([Fudala and Iwamoto, 1987], [Horan et al., 1997] and [Jorenby et al., 1990]) or no place conditioning ([Acquas et al., 1989], [Carboni et al., 1989], [Clarke and Fibiger, 1987], [Rogers et al., 2004], [Shoaib et al., 1994] and [Shram et al., 2006]). Some potential factors that might explain the inconsistent results include age and strain of the rat, pre-exposure to nicotine, and use of a biased versus unbiased procedure (see LeFoll and Goldberg (2005) for a more detailed review).

Importantly, a majority (ca. 70\%) of the published reports of nicotine place preference have used a biased design (see LeFoll and Goldberg, 2005). In a biased design, rats are initially given at least one free-choice test before conditioning as a screen for initial compartment (context) preference. During the conditioning phase, nicotine is then paired with the initially non-preferred compartment (i.e., often termed "conditioning against a preference"). An increase in time from the pre- to post-conditioning test is considered evidence for reward in a biased design. Of note, this biased design requires a control that never receives drug to determine how compartment preference would shift as a function of mere exposure to the environment. Further, unless a preference ratio (see later) or the time in the unpaired environment was reported, any increase in time from the pre- to post-conditioning test does not necessarily reflect a "preference" for the nicotine-paired compartment. That is, the animal might continue to spend more time on its initially preferred compartment, but still show an increase in time spent in the non-preferred (drug-paired) compartment (see Bevins and Cunningham, 2006). Although this shift in preference may reflect the conditioned rewarding effects of the drug (cf. Cunningham et al., 2003), alternate explanations for the shift in preference exist, thus complicating interpretation of any place conditioning result using a biased design (e.g., [Bardo and Bevins, 2000] and [Carr et al., 1989]). For example, the change in time spent in the initially non-preferred compartment might be measuring some anxiolytic or stress reduction property of the drug that decreases initial avoidance.

This discussion highlights the need to construct a balanced apparatus (i.e., no systematic preferences for either environment), as well as use an unbiased place conditioning design to facilitate interpretation of any results. In an unbiased place conditioning design, assignment of drug-paired environment is independent of any initial preference. Interestingly, there are very few published reports of nicotine conditioning a place preference in rats using an unbiased design. Indeed, LeFoll and Goldberg (2005) in a recent review of the literature only found 4 published papers, and these were all from the same laboratory (Ashby Jr.). Further, there have only been a few additional reports of a nicotine place preference using an unbiased design with rats since this review (e.g., [Forget et al., 2005] and [Forget et al., 2006]). The doses that produced a place preference in these studies (e.g., $0.06-0.21 \mathrm{mg} / \mathrm{kg}$ ) are within the range of doses that others using the same route of administration (SC) have found no preference. With this discussion in mind, we used a balanced apparatus and an unbiased design in the present place conditioning experiments.

To our knowledge, there are no reports of place conditioning using intravenous (IV) administration of nicotine. This is somewhat surprising given the inconsistent findings using subcutaneous and intraperitoneal injections of nicotine (see LeFoll and Goldberg, 2005). Further, self-administration studies with rats consistently report that IV nicotine maintains instrumental responding over a range of doses (e.g., [Corrigall and Coen, 1989], [DeNoble and Mele, 2006], [Donny et al., 1995], [Rauhut et al., 2003] and [Shoaib et al., 1996]) indicating that IV nicotine has some reinforcing properties. Additionally, IV nicotine maintains behavior in a runway model of self-administration which combines the approach behavior of the place conditioning model and instrumental response requirement of selfadministration (Cohen and Ettenberg, 2007). Thus, one goal of the present research was to examine the ability of IV administered nicotine to condition a place preference using an unbiased design with rats. We also sought to begin examining some of the parameters important for acquisition of this nicotine-conditioned place preference: nicotine dose, number of conditioning trials, and temporal relation between chamber exposure and nicotine administration. The number of conditioning trials was expected to be important given that Pavlovian conditioned associations ([Pavlov, 1927] and [Wilkinson et al., 2006]), including place conditioning ([Brabant et al., 2005] and [Risinger and Oakes, 1996]), vary as a function of number of stimulus pairings. We also expected the temporal arrangement between context (end compartment) exposure and nicotine administration to be an important determinant of conditioning [for research and discussion of this variable (often termed "interstimulus interval") see Bevins et al. (2005), Burgos and Bevins (1997), Gibbon et al. (1977), and Pavlov (1927)]. The interstimulus interval can have especially pronounced effects in the place conditioning task. In mice, for example, alcohol produces a place pref- 
erence when administered before placement, but a place aversion when it is administered immediately after exposure to the context [((Cunningham et al., 1997) and (Cunningham et al., 2002); for a comparable effect with cocaine see Ettenberg et al. (1999)].

\section{Materials and methods}

\subsection{Animals}

Forty-five adult male Sprague-Dawley rats $(329 \pm 2.4 \mathrm{~g})$ from Harlan (Indianapolis, IN) were housed separately in polycarbonate tubs lined with wood shavings in a temperature- and humidity-controlled colony. Rat chow and water were continuously available in the home cage. All sessions were conducted during the light portion of a 12:12 h light/dark cycle. Experimental protocols were approved by the University of NebraskaLincoln IACUC and followed the "Guide for the Care and Use of Laboratory Animals" (National Research Council, 1996).

\subsection{Surgery}

Rats were anesthetized with $1 \mathrm{ml} / \mathrm{kg}$ ketamine hydrochloride $(100 \mathrm{mg} / \mathrm{ml}$, IP) followed by $0.6 \mathrm{ml} / \mathrm{kg}$ xylazine hydrochloride $(20 \mathrm{mg} / \mathrm{ml}$, IP) (Midwestern Veterinary Supply, Des Moines, IA). One end of a silastic catheter was implanted into the left external jugular vein. The other end of the catheter was fed subcutaneously around the shoulder and exited via a backmount just below the scapula. The backmount allowed access to the catheter through a metal cannula. Buprenorphine hydrochloride $(0.1 \mathrm{mg} / \mathrm{kg})$ was injected SC immediately following surgery. For the evening and day following surgery, buprenorphine $(0.5 \mathrm{mg} / \mathrm{kg})$ was available in the drinking water to mange post-surgical pain. For the evening of surgery and the following 2 days (AM and PM), the catheter was flushed with $0.1 \mathrm{ml}$ of streptokinase (ca. $8000 \mathrm{Units} / \mathrm{ml}$ ) dissolved in sterile saline mixed with heparin (30 Units/ml; Midwest Veterinary Supply, Des Moines, IA). The catheter was flushed once to twice a day for the remaining duration of the experiment with $0.2 \mathrm{ml}$ of 30 Units $/ \mathrm{ml}$ of heparinized saline. Rats were allowed 5 days of recovery before the start of an experiment. Catheter patency was assessed with a $0.05 \mathrm{ml} \mathrm{IV} \mathrm{infusion} \mathrm{of} \mathrm{xylazine}(20 \mathrm{mg} / \mathrm{ml})$ at pre-established points in the study. This concentration produces clear motor ataxia within $5 \mathrm{~s}$ if the catheter is patent (cf. [Bevins and Bardo, 2000] and [Bevins, 2005]). The 37 rats with patent catheters were included in analyses. The ' $n$ ' reported in the following sections reflect the number of patent rats in each experiment.

\subsection{Apparatus}

Place conditioning was assessed in one of two chambers with Plexiglas ceiling, front and back walls; the side walls were aluminum. Each chamber had two distinct end compartments $[40 \times 16 \times 20 \mathrm{~cm}(l \times w \times h)]$ separated by a smaller center placement area $[6.5 \times 15.5 \times 19.5 \mathrm{~cm}(l \times w \times h)]$. Interchangeable floors were used to create the distinct environments. One floor had approximately 340 holes (1.3-cm diameter) drilled into a 16-gauge aluminum sheet. The other floor was made of 1-cm stainless steel rods. Two rods were mounted side-by-side on an acrylic base with the following adjacent rod pair separated from the next pair by $1 \mathrm{~cm}$. During conditioning, a solid aluminum floor the same length as that used in the center compartment $(6.5 \mathrm{~cm})$ was placed in each end chamber nearest the wall blocking access to the center compartment. This maneuver reduced the novelty of this floor on post-conditioning choice tests. The experimental room was separate from the colony and was illuminated by a red light $(40 \mathrm{~W})$.

\subsection{Drug}

(-)Nicotine tartrate (Sigma, St Louis, MO) was dissolved in sterile saline and the $\mathrm{pH}$ was adjusted to $7.0 \pm 0.2$ with a dilute $\mathrm{NaOH}$ solution. Nicotine infusions were $0.5 \mathrm{ml} / \mathrm{kg}$ and all nicotine doses are reported as base.

\subsection{Experiment 1A: place conditioning with $0.03 \mathrm{mg} / \mathrm{kg}$ nicotine}

\subsubsection{Habituation}

Rats $(n=8)$ were attached to PE50 tubing connected to a syringe and then placed in the center compartment of the place conditioning chamber. The prescribed volume of saline was infused manually over $1 \mathrm{~s}$ and then the syringe was replaced with another syringe of sterile saline and the tubing was cleared of solution from the first syringe with $0.1 \mathrm{ml}$ of sterile saline. The tubing was then disconnected from the cannula and the rats were allowed to freely explore the entire apparatus for $10 \mathrm{~min}$.

\subsubsection{Conditioning \& testing (4 trials)}

Conditioning occurred across 8 consecutive days with one session per day. Half of the rats received $0.03 \mathrm{mg} / \mathrm{kg}$ nicotine on days $1,3,5$, and 7 , and saline on opposite days; the order of nicotine and saline was reversed for the remaining rats. During a nicotine session, the rat was placed in the paired compartment where it received an infusion of nicotine followed by $0.1 \mathrm{ml}$ of saline (see Habituation). Confinement to the paired compartment was 10 min once the tubing was detached from the cannula and the chamber ceiling closed. Saline sessions were similar to nicotine sessions except saline was infused instead of nicotine. Assignment to floor location (i.e., rod floor on left or right) and paired floor (i.e., nicotine paired with rod or hole flooring) was counterbalanced and irrespective of performance on the habituation session. Approximately $24 \mathrm{~h}$ after the last conditioning session was a drug-free (saline) choice test. Rats were placed in the center compartment and infused with saline as in the habituation session. The tubing was removed from the cannula and the rats were allowed to freely explore the entire chamber for $10 \mathrm{~min}$.

\subsubsection{Additional conditioning \& testing (4 more trials)}

Beginning the following day, conditioning was continued exactly as described above for an additional 4 conditioning trials (i.e., resulting in a total of 8 saline and 8 nicotine sessions). The drug-free test was $24 \mathrm{~h}$ after the last confinement and was identical to the previous drug-free test. 


\subsection{Experiment 1B: place conditioning with $0.01 \mathrm{mg} / \mathrm{kg}$ nicotine}

After establishing that $0.03 \mathrm{mg} / \mathrm{kg}$ nicotine administered IV conditioned a place preference, we sought to test a lower dose of nicotine $(0.01 \mathrm{mg} / \mathrm{kg}, \mathrm{IV})$. A separate and experimentally naive set of rats $(n=7)$ was conditioned and tested as described for Experiment $1 \mathrm{~A}$ except $0.01 \mathrm{mg} / \mathrm{kg}$ nicotine was used instead of $0.03 \mathrm{mg} / \mathrm{kg}$ nicotine. All factors were counterbalanced as much as allowed by the sample size.

\subsection{Experiment 2: role of interstimulus interval}

\subsubsection{Habituation}

Habituation was similar to Experiments $1 \mathrm{~A}$ and 1B. Rats were randomly assigned to the $-10,0$, or $+10 \mathrm{~min}$ group. The group name denotes the time between the intravenous infusion and placement in the chamber. Thus for habituation, the -10 min group $(n=7)$ was infused with saline and returned to the home cage for $10 \mathrm{~min}$ before placement in the center compartment of the place conditioning chamber. Rats in the $0 \mathrm{~min}$ group $(n=8)$ were infused immediately after placement in the chamber. This group served as a replication of Experiment 1A. The +10 min group $(n=7)$ was infused 10 min after placement (i.e., immediately after removal from the apparatus).

\subsubsection{Conditioning \& testing (4 trials)}

Conditioning proceeded in a manner similar to Experiment 1A. Each infusion (saline and $0.03 \mathrm{mg} / \mathrm{kg}$ nicotine) was administered at the time point denoted by group assignment (i.e., $-10,0$, or $+10 \mathrm{~min})$. The drug-free-choice test was identical to the previous experiment.

\subsubsection{Additional conditioning \& testing (4 more trials)}

As in Experiment 1A, conditioning was continued for an additional 4 conditioning trials before conducting another drugfree test.

\subsection{Dependent measures}

For each choice test, we calculated a preference ratio using the following formula: time spent in the nicotine-paired compartment $\div$ (time spent in the nicotine-paired compartment +time spent in the unpaired compartment). A preference ratio of 0.5 indicates no preference for either end compartment; a preference ratio greater than 0.5 indicates a preference for the paired compartment. Time in each compartment was scored during the test sessions. A rat was considered in a specific compartment when its front paws, head, and shoulders were in that compartment. Table 1 shows the mean time spent in the paired, unpaired (saline), and center compartments across the three experiments. Horizontal activity in each end compartment was also scored during each of the test sessions by counting the number of times the head and shoulders of the rat crossed a line that bisected each end compartment. Interobserver reliabilities for each measure was conducted from video by an observer naive to the experimental conditions. The Pearson-product moment correlations were high for the 66 observations made by both observers for time spent in each compartment, $r=0.93$, $p<0.001$, and for the 60 observations in common for line crosses, $r=0.97, p<0.001$.

\subsection{Data analyses}

One-way repeated measures ANOVAs were used to examine preference ratios across the 3 test sessions (habituation, 4 conditioning trials, and 8 conditioning trials) for Experiment $1 \mathrm{~A}$ and 1B. A mixed two-way ANOVA with Session as the within-subject repeated factor and Interstimulus Interval as the between-subjects factor was used to analyze preference ratios for Experiment 2. Post-hoc analyses prompted by a significant $F$-value utilized one-sample $t$-tests to compare each preference ratio to a hypothetical value of 0.5 (i.e., the value indicating no preference). For analyses, activity counts were converted to a rate measure by dividing the number of line crosses in an end compartment by the time in seconds spent in that end compartment. A two-way ANOVA with Compartment and Session as the within-subject repeated measures factors was used to analyze activity data in Experiment $1 \mathrm{~A}$ and $1 \mathrm{~B}$. Activity from Experiment 2 was analyzed using a mixed three-way ANOVA with Compartment and Session as repeated within-subject factors and Interstimulus Interval as the between-subjects factor. A significant interaction for activity data prompted post-hoc Fisher's Least Significance Difference (LSD) tests. Comparisons were limited to those relevant for the significant interaction. Statistical significance was declared using a two-tailed rejection region of 0.05 .

Table 1.

Mean time (seconds) in each compartment of the chamber during each drug-free test ( \pm 1 SEM)

\begin{tabular}{|c|c|c|c|c|c|c|c|c|c|}
\hline & \multicolumn{3}{|l|}{ Habituation } & \multicolumn{3}{|c|}{4 Conditioning trials } & \multicolumn{3}{|c|}{8 Conditioning trials } \\
\hline & Paired & Unpaired & Center & Paired & Unpaired & Center & Paired & Unpaired & Center \\
\hline \multicolumn{10}{|c|}{ Experiment $I A$} \\
\hline $0.03 \mathrm{mg} / \mathrm{kg}$ & $249.6(8.7)$ & $255.4(8.4)$ & $95.06(10.8)$ & $223.4(24.0)$ & $230.3(22.0)$ & $146.3(13.2)$ & $298.6(23.5)$ & $172.7(23.2)$ & $128.6(15.8)$ \\
\hline \multicolumn{10}{|c|}{ Experiment $I B$} \\
\hline $0.01 \mathrm{mg} / \mathrm{kg}$ & $280.0(11.4)$ & $255.3(7.5)$ & $64.8(7.2)$ & $240.5(15.6)$ & $235.5(19.0)$ & $124.0(9.5)$ & $221.3(39.9)$ & $280.4(48.8)$ & $98.3(17.5)$ \\
\hline \multicolumn{10}{|c|}{ Experiment 2} \\
\hline$-10 \mathrm{~min}$ & $248.1(7.0)$ & $249.8(7.5)$ & $102.1(5.2)$ & $258.4(30.8)$ & $241.6(25.7)$ & $100.0(14.4)$ & $336.7(30.3)$ & $173.8(26.8)$ & $89.5(13.4)$ \\
\hline $0 \mathrm{~min}$ & $258.7(10.9)$ & $257.7(12.9)$ & $83.6(8.7)$ & $277.7(21.0)$ & $217.8(13.8)$ & $104.5(11.5)$ & $315.7(23.1)$ & $160.9(18.1)$ & $123.5(16.3)$ \\
\hline$+10 \mathrm{~min}$ & $216.8(30.6)$ & $292.9(42.3)$ & $90.2(13.5)$ & $228.9(17.8)$ & $250.5(17.1)$ & $120.6(7.6)$ & $251.7(27.4)$ & $240.4(29.3)$ & $108.0(10.5)$ \\
\hline
\end{tabular}



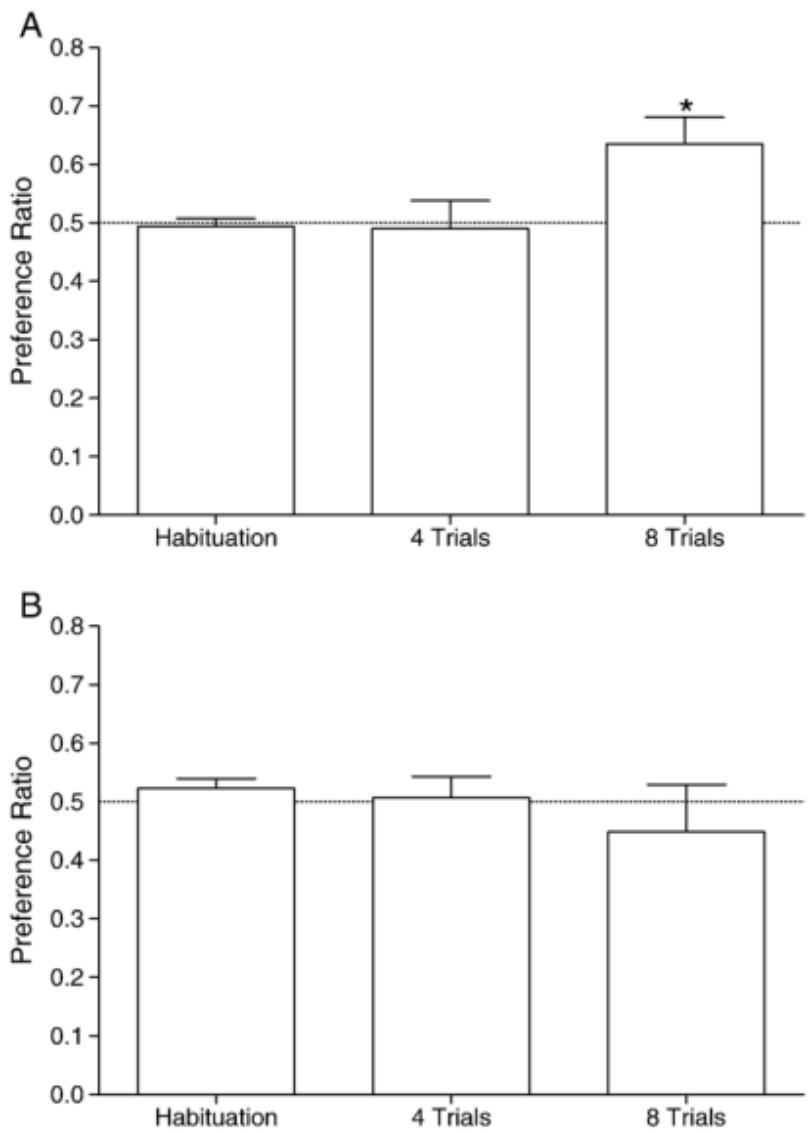

Figure 1. Panel A shows for each test session the mean preference ratios $(+1$ SEM) for rats $(n=8)$ in Experiment 1A that were conditioned with $0.03 \mathrm{mg} /$ $\mathrm{kg}$ nicotine administered IV. Panel B shows the mean preference ratios $(+1$ SEM) for rats $(n=7)$ in Experiment 2A that were conditioned with $0.01 \mathrm{mg} /$ kg nicotine administered IV. *indicates significant difference $(p<0.05)$ compared to hypothetical value of 0.5 (i.e., no preference).

\section{Results}

\subsection{Experiment 1A: place conditioning with $0.03 \mathrm{mg} / \mathrm{kg}$ nicotine}

Preference scores on each of the drug-free tests are shown in Figure 1A. There was a main effect of Session, $F(2,14)=4.07$, $p=0.04$. The preference ratios for habituation and 4 condition- ing trials were not different from $0.5, t \mathrm{~s}<1$. However, $0.03 \mathrm{mg} /$ $\mathrm{kg}$ nicotine administered IV was able to condition a place preference after 8 conditioning trials as indicated by a preference ratio significantly above $0.5, t(7)=2.93, p=0.022$. Activity scores are shown in Table 2. Although the main effect of Compartment and Session for activity were not significant, $F \mathrm{~s} \leq 2.32, p \mathrm{~s} \geq 0.17$, there was a Compartment $\times$ Session interaction, $F(2,14)=4.80, p=0.026$. None of the follow-up Fisher's LSD comparisons were significant $(\mathrm{LSD}=0.08)$.

\subsection{Experiment 1B: place conditioning with $0.01 \mathrm{mg} / \mathrm{kg}$ nicotine}

Preference scores for rats conditioned with $0.01 \mathrm{mg} / \mathrm{kg}$ nicotine are shown in Figure 1B. There was no main effect of Session, $F \mathrm{~s}<1$, indicating that $0.01 \mathrm{mg} / \mathrm{kg}$ nicotine administered IV did not produce a place preference after 4 or 8 conditioning trials. None of the $F$-values for activity were significant, $F \mathrm{~s} \leq 2.71, p \mathrm{~s} \geq 0.11$, (data shown in Table 2).

\subsection{Experiment 2: role of interstimulus interval}

Preference scores across the test sessions are shown in Figure 2. A mixed ANOVA on the preference scores revealed a main effect of Session, $F(2,38)=5.98, p=0.006$, and Group, $F(1,19)=6.05, p=0.009$; the Session $\times$ Group interaction was not significant, $F<1$. Follow-up analysis indicated that preference ratios were significantly above 0.5 after 8 conditioning trials for the -10 min group, $t(6)=2.84, p=0.029$, and the 0 min group, $t(7)=4.73, p=0.003$, denoting that these temporal relations produced a place preference after 8 conditioning trials. No other preference ratio differed from the hypothetical value of 0.5 , $t \mathrm{~s} \leq 1.67, p \mathrm{~s} \geq 0.14$. For activity, the Compartment $\times$ Session interaction was significant, $F(2,36)=5.45, p=0.01$; the main effects and remaining interactions for activity were not significant, $F \mathrm{~s} \leq 3.06, p \mathrm{~s} \geq 0.08$, (see Table 2). None of the follow-up Fisher's LSD comparisons were significant $(\mathrm{LSD}=0.15)$.

\section{Discussion}

We found that intravenously administered nicotine $(0.03 \mathrm{mg} /$ $\mathrm{kg}$ ) conditioned a place preference after 8 conditioning trials. This conditioned preference was observed whether nicotine was infused $10 \mathrm{~min}$ or immediately before placement in the paired

Table 2.

Mean activity counts per second in each end compartment during each drug-free test ( \pm 1 SEM)

\begin{tabular}{|c|c|c|c|c|c|c|}
\hline & \multicolumn{2}{|l|}{ Habituation } & \multicolumn{2}{|c|}{4 Conditioning trials } & \multicolumn{2}{|c|}{8 Conditioning trials } \\
\hline & Paired & Unpaired & Paired & Unpaired & Paired & Unpaired \\
\hline \multicolumn{7}{|l|}{ Experiment $1 \mathrm{~A}$} \\
\hline \multicolumn{7}{|l|}{ Experiment $1 B$} \\
\hline $0.01 \mathrm{mg} / \mathrm{kg}$ & $0.11(0.01)$ & $0.11(0.02)$ & $0.16(0.03)$ & $0.16(0.04)$ & $0.16(0.07)$ & $0.13(0.07)$ \\
\hline $0 \mathrm{~min}$ & $0.13(0.03)$ & $0.13(0.02)$ & $0.14(0.06)$ & $0.18(0.08)$ & $0.13(0.06)$ & $0.22(0.11)$ \\
\hline$+10 \mathrm{~min}$ & $0.12(0.04)$ & $0.11(0.05)$ & $0.11(0.06)$ & $0.10(0.08)$ & $0.13(0.06)$ & $0.12(0.05)$ \\
\hline
\end{tabular}


context for $10 \mathrm{~min}$. Infusing nicotine immediately after removal from the paired context did not produce place conditioning. At the $0.03 \mathrm{mg} / \mathrm{kg}$ dose of nicotine, 4 conditioning trials were not sufficient to condition a preference regardless of the interstimulus interval. Finally, the $0.01 \mathrm{mg} / \mathrm{kg}$ dose of nicotine when infused immediately upon placement in the environment did not condition a place preference after 4 or 8 conditioning trials.

For our initial attempt (i.e., Experiment 1A) we selected a dose of nicotine $(0.03 \mathrm{mg} / \mathrm{kg})$ that has been shown to maintain self-administration in rats across many laboratories (e.g., [Bevins, in press], [Corrigall and Coen, 1989], [DeNoble and Mele, 2006], [Donny et al., 1995], [Rauhut et al., 2003], [Shoaib et al., 1996] and [Cohen and Ettenberg, 2007]). Although there are some notable differences between what processes might be under investigation in place conditioning versus self-administration, there is also significant overlap in the list of drugs that will condition approach behavior and maintain instrumental responding (see Bardo and Bevins, 2000). Of note, this self-administered dose of nicotine required 8 conditioning trials to condition a place preference -4 trials was not sufficient. This result is in concordance with those recently reported by Cohen and Ettenberg (2007). A conditioned increase in run speed down a straight alley was observed with $0.03 \mathrm{mg} / \mathrm{kg}$ nicotine IV and this increase appeared after more than 6 conditioning trials.

The lack of a nicotine-conditioned place preference after 4 trials was predicted by a casual observation made during the experiment. That is, rats were consistently defecating on the first few trials, with most stopping by the third conditioning trial. This observation was highly salient to us given that rats in our laboratory do not defecate to this extent in this apparatus when given cocaine or amphetamine. The defecation might be a result of the peripheral actions of nicotine which has been shown to stimulate intestinal smooth muscle and increase fecal pellets in rats (Aikawa and Ohmori, 2000). Alternatively, defecation has been used as a measure of fear and aversion (cf. [Bevins et al., 1997], [Fanselow, 1986] and [Hunt and Otis, 1953]) and suggested to us that the earlier exposures to nicotine might have some of these qualities (cf. Parker and Carvell, 1986). Such qualities could compete with any early rewarding effect of nicotine thus preventing acquisition of a conditioned place preference. Although we understand the possible difficulties with deriving conclusions from such observation, we felt that it was important to report this observation since it provided part of the impetus for conducting an additional four conditioning trials.

This observation also provided the impetus for assessing the lower dose of nicotine $(0.01 \mathrm{mg} / \mathrm{kg})$ in Experiment 1B. This dose of nicotine is on the lower end of the dose-effect curve that can maintain self-administration (e.g., Rauhut et al., 2003). Thus, we were looking for a dose that might not evoke early defecation, but have some rewarding effects. The $0.01 \mathrm{mg} / \mathrm{kg}$ dose of nicotine did not produce the early defecation nor did it condition a place preference. Notably, this dose of IV nicotine did not condition an increase in running speed in the Cohen and Ettenberg (2007) study even after 21 trials. Thus, under the present set of experimental parameters we found no evidence for reward at the $0.01 \mathrm{mg} / \mathrm{kg}$ dose. Additional manipulations such as more conditioning trials and briefer chamber exposure with this lower dose of nicotine will be of interest in future studies.
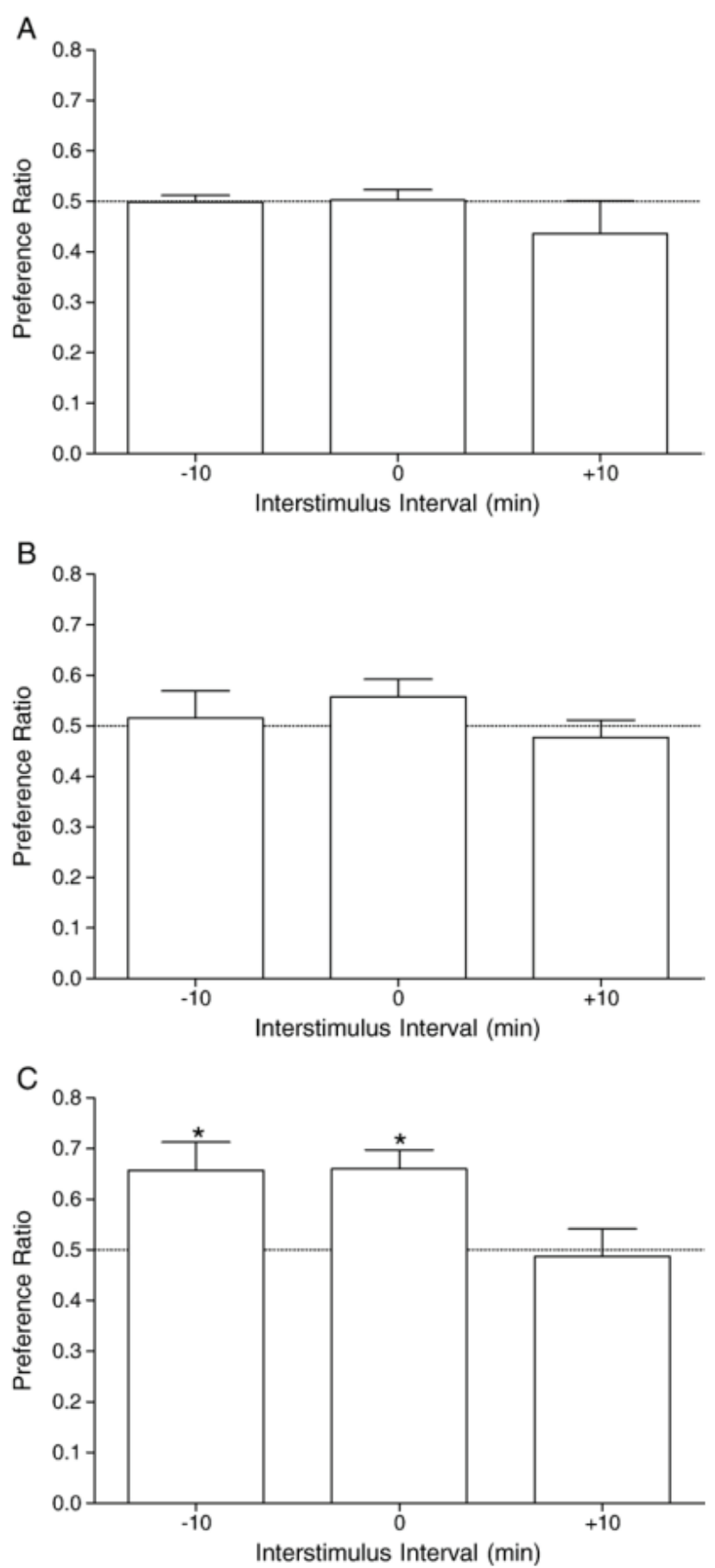

Figure 2. Panel A shows the mean preference ratio (+ 1 SEM) for the habituation phase of Experiment 2 for rats that were assigned to groups $-10 \mathrm{~min}$ $(n=7), 0$ min $(n=8)$, and $+10 \min (n=7)$. Panel B shows the mean preference ratio (+ 1 SEM) after 4 conditioning trials for each group in Experiment 2. Panel $\mathrm{C}$ shows the mean preference ratio ( +1 SEM) for each group after 8 conditioning trials. $*$ indicates significant difference $(p<0.05)$ compared to hypothetical value of 0.5 (i.e., no preference).

There is a substantial Pavlovian conditioning literature indicating the importance of the temporal arrangement between the to-be-conditioned stimulus and the reinforcer (unconditioned stimulus) for acquisition of conditioned responding. The conditioning tasks demonstrating the importance of the interstim- 
ulus interval have been as varied as eye-blink conditioning in humans (McAllister, 1953), aversive conditioning in goldfish (Bitterman, 1964), key-peck autoshaping in pigeons (Gibbon et al., 1977), context fear conditioning in rats (Bevins and Ayres, 1995), nicotine-conditioned hyperactivity in rats (Bevins et al., 2005), and ethanol place conditioning in mice (Cunningham et al., 1997). The present research extended this list to include place conditioning with IV administered nicotine. In brief, $0.03 \mathrm{mg} / \mathrm{kg}$ nicotine administered immediately or $10 \mathrm{~min}$ before confined exposure to the paired environment for $10 \mathrm{~min}$ conditioned a place preference after 8 conditioning trials. IV administration of nicotine immediately after removal from the paired compartment (i.e., -10 min group) had no apparent effect on choice behavior after 4 or 8 conditioning trials (i.e., no approach or avoidance tendencies). This data pattern suggests that the rewarding effects of IV nicotine extend long enough that there is sufficient temporal contiguity between the to-bepaired compartment and nicotine to condition an appetitive association.

Interestingly, under some experimental protocols the interstimulus interval can reveal different motivational properties of the same drug. For example, alcohol $(2 \mathrm{~g} / \mathrm{kg}, 20 \% \mathrm{v} / \mathrm{v})$ given IP to mice conditioned a place preference when administered before placement in the paired context, but the same dose conditioned an aversion when administered immediately after exposure to the context [Cunningham et al. (1997); see also Ettenberg et al. (1999) for research with cocaine]. Although we did not find evidence for this dual property/opponent process for nicotine in the present study, it will be of interest to examine different doses on IV nicotine against different interstimulus intervals, context confinement durations, etceteras.

As noted in the Introduction, much of the nicotine place conditioning research demonstrating a place "preference" has used a biased design (i.e., nicotine paired with an initially identified non-preferred compartment). Unfortunately, using a biased design introduces alternative non-reward explanations for preference shifts such as stress reduction or anxiolytic effects of the drug ([Bardo and Bevins, 2000], [Carr et al., 1989] and [Bevins and Cunningham, 2006]). To avoid such difficulties, the present research used an apparatus with balanced construction and an experimental design that was unbiased. As evidence of the balanced construction of our place conditioning apparatus, rats $(n=37)$ averaged across the three experiments in the present study spent $260.9 \pm 8.8 \mathrm{~s}$ on the rod floor and $251.8 \pm 7.4 \mathrm{~s}$ on the hole floor during habituation. By assigning rats to paired versus unpaired environment irrespective of their performance on the habituation day, the shifts in preference for the paired compartment at the $0.03 \mathrm{mg} / \mathrm{kg}$ dose of nicotine are less susceptible to non-reward interpretations.

Related to the previous discussion, some researchers have suggested that differential patterns of locomotor activity between the drug-paired and unpaired environments on the test day could complicate interpretation of a place conditioning effect (e.g., [Parker, 1992] and [Swerdlow and Koob, 1984]). This potential interaction could be important for the present research given that an environment reliably paired with nicotine administered SC comes to evoke a conditioned increase in activity on a drug-free test (e.g., [Bevins et al., 2001], [Bevins et al., 2005] and [Walter and Kuschinsky, 1989]). To assess a possible role of motor activity, we scored line crosses in each end compartment across all free-choice test sessions. Although there was a Compartment $\times$ Session interaction in each experiment showing place conditioning, the post-hoc analyses did not reveal any significant differences in activity. Further, any trend seen in the mean activity scores was the opposite of that expected if conditioned hyperactivity was evident. That is, rats were slightly more active in the unpaired compartment relative to the paired compartment. Thus, an account of our nicotine place conditioning results with $0.03 \mathrm{mg} / \mathrm{kg}$ nicotine based on conditioned alterations in motor activity seems unlikely.

Given the discussion in the previous paragraphs, we suggest that $0.03 \mathrm{mg} / \mathrm{kg}$ IV nicotine has rewarding effects that are readily measured in a place conditioning task. Conditioned associations and reward processes involving nicotine likely contribute to tobacco use and the tenacity of nicotine dependence (e.g., [Bevins and Palmatier, 2004], [Rose and Levin, 1991] and [West and Schneider, 1987]). Accordingly, a better understanding of these processes will contribute to designing better intervention strategies for smoking cessation. With this goal in mind, we suggest that the IV nicotine place conditioning protocol used in the present study might be an especially useful model for studying the processes underlying the conditioned rewarding effects of nicotine. Of course, adoption of such a recommendation will require replication by other laboratories. This replication and hence adoption might be slowed by the added technical, temporal, and fiscal burden of catheter surgeries and maintenance.

\section{Acknowledgments}

We thank Jonathan Fullner and Jill Rosno for scoring the behaviors used to assess interobserver reliability and Jessica Linkugel, Jennifer Murray, Carmela Reichel, and Amanda Struthers for their thorough read of an earlier version of this manuscript. The research and R. A. Bevins were supported by United States Public Health Service grant DA018114 and DA017086. Jamie Wilkinson was supported by Nebraska Tobacco Settlement Biomedical Research Enhancement Funds while preparing this manuscript for publication.

\section{References}

Acquas ET AL., 1989 - E. Acquas, P. L. Carboni and G. DiChiara, SCH23390 blocks drug-conditioned place-preference and place-aversion: anhedonia (lack of reward) or apathy (lack of motivation) after dopamine-receptor blockade, Psychopharmacology 99 (1989), pp. $151-155$.

Aikawa And OHMORI, 2000 - N. Aikawa and K. Ohmori, Effect of zaldaride maleate, an antidiarrheal compound, on fecal pellet output induced by hyperpropulsion in gastrointestine of rats, Jpn J Pharmacol 82 (2000), pp. 350-352.

Ashby ET AL., 2002 - C. R. Ashby Jr., M. Paul, E. L. Gardner, M. R. Gerasimov, S. L. Dewey and I. C. Lennon et al., Systemic administration of $1 \mathrm{R}, 4 \mathrm{~s}-4$ amino-cyclopent-2-ene-carboxylic acid, a reversible inhibitor of GABA transaminase, blocks expression of conditioned place preference to cocaine and nicotine in rats, Synapse 44 (2002), pp. 61-63.

Bardo and Bevins, 2000 - M. T. Bardo and R. A. Bevins, Conditioned place preference: what does it add to our preclinical understanding of drug reward?, Psychopharmacology 153 (2000), pp. 31-43. 
Bevins, $2005-$ R. A. Bevins, The reference-dose place conditioning procedure yields a graded dose-effect function, Int J Comp Psychol 18 (2005), pp. 101-111.

Bevins, in press - R. A. Bevins, Altering the motivational function of nicotine through conditioning processes. In R. A. Bevins and A. R. Caggiula (Eds.), The motivational impact of nicotine and its role in tobacco use: The 55th Nebraska Symposium on Motivation in press.

Bevins and Ayres, 1995 - R. A. Bevins and J. J. B. Ayres, One-trial context fear conditioning as a function of the interstimulus interval, Anim Learn Behav 23 (1995), pp. 400-410.

Bevins and Bardo, $2000-$ R. A. Bevins and M. T. Bardo, Conditioned increase in place preference by access to novel objects: antagonism by MK-801, Behav Brain Res 99 (2000), pp. 53-60.

Bevins and Cunningham, 2006 - R. A. Bevins and C. L. Cunningham, Place conditioning: a methodological analysis. In: M. Anderson, Editor, Tasks and Techniques: A Sampling of Methodologies for the Investigation of Animal Learning, Behavior, and Cognition, Nova Science Publisher, Hauppauge NY (2006), pp. 99-110.

Bevins and Palmatier, 2004 - R. A. Bevins and M. I. Palmatier, Extending the role of associative learning processes in nicotine addiction, Behav Cogn Neurosci Rev 3 (2004), pp. 143-158.

Bevins ET AL., 1997 - R. A. Bevins, J. E. McPhee, A. S. Rauhut and J. J. B. Ayres, Converging evidence for one-trial context fear conditioning with an immediate shock: importance of shock potency, J Exp Psychol Anim Behav Process 23 (1997), pp. 312-324.

Bevins ET AL., 2001 - R. A. Bevins, J. Besheer and K. S. Pickett, Nicotine-conditioned locomotor activity in rats: dopaminergic and GABAergic influences on conditioned expression, Pharmacol Biochem Behav 68 (2001), pp. 135-145.

Bevins $E T$ AL., 2005 - R. A. Bevins, S. Eurek and J. Besheer, Timing of conditioned response in a nicotine locomotor conditioning preparation: manipulations of the temporal arrangement between context cues and drug administration, Behav Brain Res 59 (2005), pp. 135-143.

Bitterman, 1964 - M. E. Bitterman, Classical conditioning in the goldfish as a function of the CS-US interval, J Comp Physiol 58 (1964), pp. 359-366.

Brabant et AL., 2005 - C. Brabant, E. Quertemont and E. Tirelli, Influence of the dose and the number of drug-context pairings on the magnitude and the long-lasting retention of cocaine-induced conditioned place preference in C57BL/6J mice, Psychopharmacology 180 (2005), pp. 33-40.

Burgos and Bevins, 1997 - J. E. Burgos and R. A. Bevins, The P-system: a scheme for organizing Pavlovian procedures, Behav Res Methods Instrum Comput 29 (1997), pp. 473-483.

Calcagnetti And Schechter, 1994 - D. J. Calcagnetti and M. D. Schechter, Nicotine place preference using the biased method of conditioning, Prog Neuropsychopharmacol Biol Psychiatry 18 (1994), pp. 925-933.

Carboni et al., 1989 - E. Carboni, E. Acquas, P. Leone and G. DiChiara, $5 \mathrm{HT}_{3}$ receptor antagonists block morphine- and nicotine - but not amphetamine-induced reward, Psychopharmacology 97 (1989), pp. $175-178$.

Carr et al., 1989 - G. D. Carr, H. C. Fibiger and A. G. Phillips, Conditioned place preference as a measure of drug reward. In: J. M. Liebman and S. J. Cooper, Editors, The neuropharmacological basis of reward, Clarendon Press, Oxford (1989), pp. 264-319.

Center for Disease Control, 2005 - Center for Disease Control, Cigarette smoking among adults - United States, 2004, MMWR Weekly vol. 54 (2005), pp. 1121-1124 Available from:

http://www.cdc.gov/mmwr/preview/mmwrhtml/mm5444a2.htm.

Clarke and Fibiger, 1987 - P. B. Clarke and H. C. Fibiger, Apparent absence of nicotine-induced conditioned place preference in rats, Psychopharmacology 92 (1987), pp. 84-88.
Cohen and Ettenberg, 2007 - A. Cohen and A. Ettenberg, Motivational effects of nicotine as measured in a runway model of drug self-administration, Behav Pharmacol 18 (2007), pp. 265-271.

Corrigall and Coen, 1989 - W. A. Corrigall and K. M. Coen, Nicotine maintains robust self-administration in rats on a limited access schedule, Psychopharmacology 99 (1989), pp. 473-478.

Cunningham and Noble, 1992 - C. Cunningham and D. Noble, Methamphetamine-induced conditioned place preference or aversion depending on dose and presence of drug, Ann N Y Acad Sci 654 (1992), pp. $431-433$.

Cunningham et AL., 1997 - C. L. Cunningham, D. M. Okorn and C. E. Howard, Interstimulus interval determines whether ethanol produces conditioned place preference or aversion in mice, Anim Learn Behav 25 (1997), pp. 31-42.

Cunningham et al., 2002 - C. L. Cunningham, J. M. Clemens and T. L. Fidler, Injection timing determines whether intragastric ethanol produces conditioned place preference or aversion in mice, Pharmacol Biochem Behav 72 (2002), pp. 659-668.

Cunningham ET AL., 2003 - C. L. Cunningham, N. K. Ferree and M. A. Howard, Apparatus bias and place conditioning with ethanol in mice, Psychopharmacology 170 (2003), pp. 409-422.

DeNoble and Mele, 2006 - V. J. DeNoble and P. C. Mele, Intravenous nicotine self-administration in rats: effects of mecamylamine, hexamethonium and naloxone, Psychopharmacology 184 (2006), pp. 266-272.

Dewey ET AL., 1999 - S. L. Dewey, J. D. Brodi, M. R. Gerasimov, B. Horan, E. L. Gardner and C. R. Ashby Jr., A pharmacological strategy for the treatment of nicotine addiction, Synapse 31 (1999), pp. 76-86.

Donny et AL., 1995 - E. C. Donny, A. R. Cagguila, A. Knopf and C. Brown, Nicotine self-administration in rats, Psychopharmacology 122 (1995), pp. 390-394.

Erb and Parker, 1994 - S. M. Erb and L. A. Parker, Individual differences in novelty-induced activity do not predict strength of amphetamine-induced place conditioning, Pharmacol Biochem Behav 48 (1994), pp. 581-586.

Ettenberg et AL., 1999 - A. Ettenberg, M. A. Raven, D. A. Danluck and B. D. Necessary, Evidence for opponent-process actions of intravenous cocaine, Pharmacol Biochem Behav 64 (1999), pp. 507-512.

FAnselow, 1986 - M. S. Fanselow, Associative vs. topographical accounts of the immediate shock-freezing deficit in rats: Implications for the response selection roles governing species-Specific defensive reactions, Learn Motiv 17 (1986), pp. 16-39.

Forget ET AL., 2005 - B. Forget, M. Hamon and M. H. Thiebot, Cannabinoid $\mathrm{CB}_{1}$ receptors are involved in motivational effects of nicotine in rats, Psychopharmacology 181 (2005), pp. 722-734.

Forget ET AL., 2006 - B. Forget, S. Barthelemy, F. Saurini, M. Hamon and M. H. Thiebot, Differential involvement of the endocannabinoid system in short- and long-term expression of incentive learning supported by nicotine in rats, Psychopharmacology 189 (2006), pp. 59-69.

Fudala And Iwamoto, 1986 - P. J. Fudala and E. T. Iwamoto, Further studies on nicotine-induced conditioned place preference in rats, Pharmacol Biochem Behav 25 (1986), pp. 1041-1049.

Fudala and Iwamoto, 1987 - P. J. Fudala and E. T. Iwamoto, Conditioned aversion after delay place conditioning with nicotine, Psychopharmacology 92 (1987), pp. 376-381.

Fudala ET AL., 1985 — P. J. Fudala, D. W. Teoh and E. T. Iwamoto, Pharmacologic characterization of nicotine-induced conditioned place preference, Pharmacol Biochem Behav 22 (1985), pp. 237-241.

Gehrke et al., 2003 - B. Gehrke, S. Harrod, W. Cass and M. Bardo, The effect of neurotoxic doses of methamphetamine on methamphetamine-conditioned place preference in rats, Psychopharmacol 166 (2003), pp. 249-258.

GibBon ET AL., 1977 — J. Gibbon, M. D. Baldock, C. Locurto, L. Gold 
and H. S. Terrace, Trial and intertrial durations in autoshaping, $J$ Exp Psychol Anim Behav Process 3 (1977), pp. 264-284.

Grabus ET AL., 2006 - S. D. Grabus, B. R. Martin, S. E. Brown and M. I. Damaj, Nicotine place preference in the mouse: influences of prior handling, dose and strain and attenuation by nicotinic receptor antagonists, Psychopharmacology 184 (2006), pp. 456-463.

Horan ET AL., 1997 — B. Horan, M. Smith, E. L. Gardner, M. Lepore and C. R. Ashby Jr., (-)-nicotine produces conditioned place preference in Lewis but not Fischer 344 rats, Synapse 26 (1997), pp. 93-94.

Horan ET AL., 2001 - B. Horan, E. L. Gardner, S. L. Dewey, J. L. Brodie and C. R. Ashby Jr., The selective sigma(1) receptor agonist, 1-(3,4dimethoxyphenethyl)-4-(phenylpropyl)piperazine (SA4503), blocks the acquisition of the conditioned place preference response to (-)nicotine in rats, Eur J Pharmacol 26 (2001), pp. R1-R2.

Hunt and Otis, 1953 - H. F. Hunt and L. S. Otis, Conditioned and unconditioned emotional defecation in the rat, J Comp Physiol Psych $\mathbf{4 6}$ (1953), pp. 378-382.

JoRenBy ET AL., 1990 - D. E. Jorenby, R. E. Steinpreis, J. E. Sherman and T. B. Baker, Aversion instead of preference learning indicated by nicotine place conditioning in rats, Psychopharmacology 101 (1990), pp. 533-538.

LeFoll and Goldberg, 2005 - B. LeFoll and S. R. Goldberg, Nicotine induces conditioned place preference over a large range of doses in rats, Psychopharmacology 178 (2005), pp. 481-492.

LetT, 1989 - B. T. Lett, Repeated exposures intensify rather than diminish the rewarding effects of amphetamine, morphine, and cocaine, Psychopharmacology 98 (1989), pp. 357-362.

McAllister, 1953 - W. R. McAllister, Eyelid conditioning as a function of the CS-US interval, J Exp Psych 45 (1953), pp. 417-422.

McGinnis and Foege, 1993 - J. M. McGinnis and W. H. Foege, Actual causes of death in the United States, J Am Med Assoc 270 (1993), pp. $2207-2212$.

Mokdad et al., 2004 - A. H. Mokdad, J. S. Marks, D. F. Stroup and J. L. Gerberding, Actual causes of death in the United States, 2000, J Am Med Assoc 291 (2004), pp. 1238-1245.

National Institute on Drug Abuse, 2006 - National Institute on Drug Abuse, Cigarettes and other tobacco products, NIDA Info Facts (2006) July, Available from: www.drugabuse.gov/pdf/infofacts/Tobacco06.

National Research Council, 1996 - National Research Council, Guide for the care and use of laboratory animals, National Academy Press, Washington, DC (1996).

Nomikos and Spyraki, 1988 - G. G. Nomikos and C. Spyraki, Cocaineinduced place conditioning: importance of route of administration and other procedural variables, Psychopharmacology 94 (1988), pp. $119-125$.

O'Dell ET AL., 1996 - L. E. O’Dell, T. V. Khroyan and J. L. Neisewander, Dose-dependent characterization of the rewarding and stimulant properties of cocaine following intraperitoneal and intravenous administration in rats, Psychopharmacology 123 (1996), pp. 144-153.

Panksepp et AL., 2004 - J. Panksepp, C. Nocjar, J. Burgdorf, J. B. Panksepp and R. Huber, The role of emotional systems in addiction: a neuroethological perspective, Nebr Symp Motiv 50 (2004), pp. 85-126.

PARKer, 1992 - L. A. Parker, Place conditioning in a three- or fourchoice apparatus: role of stimulus novelty in drug-induced place conditioning, Behav Neurosci 106 (1992), pp. 294-306.

Parker and Carvell, 1986 - L. A. Parker and T. Carvell, Orofacial and somatic responses elicited by lithium-, nicotine-, and amphetaminepaired sucrose solution, Pharmacol Biochem Behav 24 (1986), pp. 883-887.
Pavlov, 1927 - I. P. Pavlov, Conditioned reflexes, Dover, New York (1927).

Randall ET AL., 1998 - C. K. Randall, P. J. Kraemer and M. T. Bardo, Morphine-induced conditioned place preference in preweanling and adult rats, Pharmacol Biochem Behav 60 (1998), pp. 217-222.

Rauhut ET AL., 2003 - A. S. Rauhut, N. Neugebauer, L. P. Dwoskin and M. T. Bardo, Effect of bupropion on nicotine self-administration in rats, Psychopharmacology 169 (2003), pp. 1-9.

Risinger And OAKes, 1995 - F. O. Risinger and R. A. Oakes, Nicotineinduced conditioned place preference and conditioned aversion in mice, Pharmacol Biochem Behav 51 (1995), pp. 457-461.

Risinger AND OAKES, 1996 - F. O. Risinger and R. A. Oakes, Dose- and conditioning trial-dependent ethanol-induced conditioned place preference in Swiss Webster mice, Pharmacol Biochem Behav 55 (1996), pp. 117-123.

Rogers ET AL., 2004 - D. T. Rogers, S. Barron and J. M. Littleton, Neonatal ethanol exposure produces a hyperalgesia that extends into adolescence, and is associated with increased analgesic and rewarding properties of nicotine in rats, Psychopharmacology 171 (2004), pp. 204-211.

Rose AND Levin, 1991 - J. E. Rose and E. D. Levin, Inter-relationship between conditioned and primary reinforcement in the maintenance of cigarette smoking, Br J Addict 86 (1991), pp. 605-609.

SHOAIB ET AL., 1994 - M. Shoaib, I. P. Stolerman and R. C. Kumar, Nicotine-induced place preferences following prior nicotine exposure in rats, Psychopharmacology 113 (1994), pp. 445-452.

SHOAiB ET AL., 1996 - M. Shoaib, C. W. Schindler and S. R. Goldberg, Nicotine self-administration in rats: strain and nicotine pre-exposure effects on acquisition, Psychopharmacology 129 (1996), pp. 35-43.

Shram ET AL., 2006 - M. J. Shram, D. Funk, L. Zhaoxia and A. D. Le, Periadolescent and adult rats respond differently in tests measuring the rewarding and aversive effects of nicotine, Psychopharmacology 186 (2006), pp. 201-208.

Stolerman, 1991 - I. P. Stolerman, Behavioral pharmacology of nicotine: multiple mechanisms, $B r J$ Addict 86 (1991), pp. 533-536.

Stolerman and Jarvis, 1995 - I. P. Stolerman and M. J. Jarvis, The scientific case that nicotine is addictive, Psychopharmacology 117 (1995), pp. 2-10.

Swerdlow and Koob, 1984 - N. R. Swerdlow and G. F. Koob, Restrained rats learn amphetamine-conditioned locomotion, but not place preference, Psychopharmacology 84 (1984), pp. 163-166.

TzschentKe, 1998 - T. M. Tzschentke, Measuring reward with the conditioned place preference paradigm: a comprehensive review of drug effects, recent progress and new issues, Prog Neurobiol 56 (1998), pp. 613-672.

Walter and Kuschinsky, 1989 - S. Walter and K. Kuschinsky, Conditioning of nicotine effects on motility and behaviour in rats, NaunynSchmiedeberg's Arch Pharmacol 339 (1989), pp. 208-213.

West and Schneider, 1987 R. West and N. Schneider, Craving for cigarettes, Br J Addict 82 (1987), pp. 407-415.

WiLKINSON ET AL., 2006 - J. L. Wilkinson, J.E. Murray, C. Li, S.M. Wiltgen, R. D. Penrod and S. A. Berg et al., Interoceptive Pavlovian conditioning with nicotine as the conditional stimulus varies as a function of number of conditioning trials and unpaired sucrose deliveries, Behav Pharmacol 17 (2006), pp. 161-172. 